\title{
TECNOLOGÍAS DE LA DEMOCRACIA: LA VIEJA INVENCIÓN DEL FUTURO
}

Julieta Espinosa

Universidad Autónoma del Estado de Morelos, México

http://dx.doi.org/10.5209/NOMA.54875

Resumen.- La organización de las sociedades en el mundo occidental se desarrolla al mezclar modos de vida específicos para todos y cada uno de los individuos, con una perspectiva de futuro para la sociedad en conjunto. El ejercicio de la democracia implementada, desde fines del siglo XVIII, ha ofrecido alcanzar, de manera colectiva, la civilización, el progreso y prácticas que reflejen una calidad de vida etiquetada como digna y justa. En este texto, se exponen algunos procesos, a través de los cuales, se proponen formas de vida cotidianas exaltadas como valiosas porque, justamente, evidenciarán que la sociedad va en pos de la democracia...inalcanzable.

Palabras clave: tecnologías, democracia, Foucault, civilización, progreso, cuerpos.

Abstract. In the Western World, the organization of the societies combines differentlifestyles for all and each one of the individuals with a future perspective for the entire society. The Democracy implemented at the end of the XVIII Century proposes to achieve progress and civilization as well as practices that will allow a dignified and just life. In this paper, we present some of the paths through which it is offering ways of daily life considered as values because of they show that the society runs behind the democracy... unreached.

Key Words: technologies, democracy, Foucault, civilization, progress, bodies.

\section{Introducción.}

Estudiar, en el mundo occidental, las formas de organización de las sociedades desde las instituciones (Goffman, North 2001), o el Estado (Smith, 1776;Habermas, Rosanvallon, 2011;Giddens, 2001), o el derecho (Hegel,Rawls,Elster 1998), o los actores (Touraine, 2013) ha permitido comprensiones del presente que se combinan, casi en todos los casos antes citados (exceptuemos a Goffman, 1973), con una propuesta de adecuación, de mejora o de reforma, que conduciría, eventualmente, a aligerar las tensiones internas de las sociedades ahí abordadas. 
Existen, también, otros estudios al respecto que, desde plataformas de análisis que van más allá de lo teórico y lo disciplinar, buscan un diagnóstico del momento sin pretender ofrecer, ni un happyend después del camino transitado, ni una recomendación optimista y de buena voluntad para el futuro (Nietzsche, 1886, Foucault, Girard, 1985, Sloterdijk, 2010, 2011, 2015; Stengers, 2009, 2013; Latour 2010, 2013).

Estas dos amplias posturas frente alanálisis tienen, como se podrá comprender, una flagrante diferencia: si bien su objeto de estudio parecería ser el mismo, el sentido que persiguen es distinto, es decir, las consecuencias que buscan provocar no coinciden. En el primer caso, además del diálogo con los colegas de la disciplina, se ofrecen reacomodos para que la idea de democracia, acuñada en el último tercio del siglo XVIII, permanezca como el punto de llegada a fortalecer y cuidar; mientras que, en el segundo, el interlocutor es, ademásdel par disciplinar, todo aquél preocupado por el presente, y que entiende que las herramientas teóricas en uso, evidentemente, autorizan y sugieren acomodos, reingenierías, matices, pero de ninguna manera allanan el camino para pensar, con otros entramados, lo que sucede.Ellos han tejido otras vías para pensar las prácticas de los hombres; es por ello que sus textos aluden' a piezas de música (Nietzsche), pinturas, fotografías, ritos (Girard, 1985), lecturas del tarot (Stengers, 2009), los juegos olímpicoso el ayuno (Sloterdijk, 2010), los presupuestos de las alcaldías o municipios, los acuerdos para distribuir droga ${ }^{2}$ en Europa, por citar algunas de las racionalidades (no teóricas, pero, por supuesto, racionalidades) que despliegan para realizar sus diagnósticos. La línea que separa, entonces, dichas posturas, no es la ambiciosa demarcación de rigor disciplinar, sino la compleja exigencia de identificar el movimiento, sus condiciones de existencia y sus puntos de llegada efectivos, en su relación con los modos para existir hic et nunc,y abiertos para pensar, con urgencia, otras maneras de comprender el hacer de los hombres en el planeta.

Este texto se inscribe en la última opción de análisis y reflexión: encontrar otros senderos para exponer una trayectoria de abordaje que focaliza, en las prácticas de los hombres, la fuerza y la dimensión de su vínculo con la idea de democracia. Es decir, se trata de identificar, profundizar y recorrer, los discursos, las acciones, las experiencias, desde los modos de pensamiento o las diferentes racionalidades, que los individuos han inaugurado para apuntalar, consolidar, fomentar, difundir,trayectorias diversas trazadas para conducir hacia la democracia.

\footnotetext{
1."Debemos leer todo, estudiar todo. Dicho de otra manera, en algún momento, es necesario tener acceso al archivo general de una época, y, la arqueología es, en sentido estricto, la ciencia de este archivo.", Foucault, $1966: 527$.

2. Para tener una idea de cómo funcionan las leyes, no es en los tratados 'sacralizados' donde hay que buscar, sino en los acuerdos para aplicarla; Foucault ejemplifica su uso diferenciado con la distribución de droga en Europa (Foucault,1975: 1587).
} 


\section{UNO. Entramado de las tecnologías de la democracia.}

Las tecnologías de la democracia, primero, no implican un objeto de estudio entre especialistas de la ciencia política (la democracia y sus implementaciones), o de la sociología (la democracia que se ha perdido o la que se debe construir para que la sociedad funcione), o de filosofía (una democracia derivada de argumentos respaldados por una racionalidad teórica-rigurosa); las "tecnologías de la democracia" es una vía para introducirse en la multiplicidad de racionalidades ${ }^{3}$ o modos de pensamiento ${ }^{4}$ que atraviesan a los individuos, asumidos comoparte de colectivos, quienes buscan, defienden, consolidan, mejoran, protegen a la democracia.

Abordar algunos ángulos de las formas de organización de las sociedades desde las tecnologías de la democracia permite, segundo, evidenciar que el ofrecimiento de vivir con base en un régimen democrático que ha guiado a los países "civilizados", o industrializados, - desarrollados, o de primer mundo, no es, desde una dimensión de sociedad, una invitación que se pueda desplegar sustentada ni en una idea única, ni exclusivamente desde las prácticas de gobierno. La 'democracia' que ha guiado a dichos países, ha estado impregnada y rodeada de "civilización", entendida como: desarrollo económico, protección social otorgada por el gobierno 'benefactor', dominio de la naturaleza que concluye en un cierto tipo de calidad de vida cotidiana, reto permanente y triunfo constante del discurso teórico sistematizado (mejor conocido como 'ciencia' y disciplinas), invitación abierta para que el individuo luche por su movilidad social, libertad de expresión y de opinión, libertad individual, competencia ${ }^{5}$ económica, cultural, política y social, derechos humanos protegidos por organismos nacionales e

3. "En una sociedad, los conocimientos, las ideas filosóficas, las opiniones de todos los días, pero también las instituciones, las prácticas comerciales y policiacas, las costumbres, todo conduce a un cierto saber implícito propio de esta sociedad.Este saber es profundamente diferente de los conocimientos que podemos encontrar en los libros científicos, las teorías filosóficas, las justificaciones religiosas, pero es ese saber el que posibilita, en un momento dado, la aparición de una teoría, de una opinión, de una práctica.",Foucault, $1966: 526$.

4. Los modos de pensamiento son, además de los discursos teóricos sistematizados, toda otra racionalidad a través de la cual los individuos se expresan: narraciones, mitos, crónicas, imágenes, danza, ritos, obras de teatro, rumores, chistes, películas, leyendas, diarios personales y un largo etcétera (cf. Espinosa, 2014: 16).

5. "Así como, históricamente, la noción democrática vino acompañada de la noción del derecho y éste estuvo basado en la propiedad (siendo desenterrado de los viejos baúles romanos), exactamente porque fue la burguesía la que, para existir políticamente, exigió las reglas que la defendieran en el mercado y defendiesen al Estado de la monopolización aristocrática, hoy la noción democrática sólo encuentra sustancia en la ambición de las masas por dos dimensiones básicas: el reconocimiento de sus perfiles sociales (autonomía) y el acceso a la decisión." (Cardoso, 1986 : 349350) 
internacionales, posibilidad para que los cambios sociales yculturales culminen en cambios jurídicos y normativos (judíos, negros, mujeres, homosexuales, adictos, indígenas, minorías, etc.), mejoría permanente en lo cotidiano sustentada en propiedades (muebles e inmuebles), una calidad de vida sustentada en prácticas individuales y colectivas para preservar el cuerpo (seguridad física, higiene social, salud, alimentos, deporte, medicamentos, condiciones laborales, vacunación, etc.), prácticas para comunicar e informar sobre temáticas que cohesionen a los individuos (educación, publicidad, medios masivos de comunicación, campañas electorales, etc.).De la misma manera, se podrían identificar los derivados de la idea de "progreso", como una trayectoria más hacia la democracia. La organización de un país bajo la democracia, independientemente de su 'status' (primer o tercer mundo, otros) en el esquema internacional, entonces, conlleva una extensa diversidad de "accesorios" que complementan la atracción de su ejercicio. Nosotros sostenemos que el decorum implementado, y sustentado en la representación de las mayorías, ha requerido, también, establecer fronteras de participacióncolectiva entre los ciudadanos que conforman a toda sociedad democrática. Porque la presencia de la "voluntad general" en las urnas (Quermonne, 1986), el ejercicio político a través del cual se adquiere voz en la democracia,escasamente ha implicado su incidencia en todas las otras prácticas que, necesariamente, conlleva toda sociedad, como los movimientos de "indignados"demostraron en 2011 (Madrid/Puerta del Sol, New York/Wall Street), por citar un ejemplo.

Por último,tercero, las tecnologías de la democracia no sólo convocan y sostienen prácticas diversas entrelazadas a partir de un hilo conductor tomado del régimen político, sino también se tejen con su contraparte: todo aquello que vaya en contra de la idea de democracia y todos sus 'derivados'incorporados; ello es una polaridad ineluctable al interior de la acción misma del pensamiento 6 (acción porque regula, norma, justifica, suspende, acelera, el hacer mismo).En otros términos, lo que encontramos en las distintas tecnologías usadas, es la exaltación de uno de los ángulos ofrecido ostentosamente, y, al mismo tiempo, lainsistente devaluación delo que no encaja ${ }^{7}$ con lo primero.

\footnotetext{
6."En ese sentido, el pensamiento es considerado como la forma misma de la acción, como la acción en tanto que implica el juego de lo verdadero y de lo falso, la aceptación o el rechazo a la regla, la relación consigo mismo y con los otros.", Foucault, 1984a: 1399.

7. Un ejemplo de contraste, lo expone G. Prieto, político y literato del siglo XIX en México, cuando escribe, en 1874, sobre la necesidad de mantener el financiamiento de lugares de refugio para niños pobres: "En la sala de asilo se salva la existencia de niños de la raza indígena, conducidos a los mercados en que se arrastran como animales o se dejan en su casa en total abandono. El hijo de la obrera, que quedaba encerrado en una pieza oscura y malsana, contrayendo enfermedades horrorosas,
} 
Es claro, por lo anterior, que los trayectos de análisis de las tecnologías de la democracia, aquí propuestos, circulan entre las condiciones de existencia de las diferentes prácticas de pensamiento y de comportamiento de los hombres, instauradas para promover $u$ obstaculizar una cierta idea de vida, de sociedad, de futuro, de naturaleza y de movimiento de los colectivos (a veces nombrados "progreso" o "civilización" o "desarrollo"); los accesorios para el ejercicio de la democracia, arriba mencionados, deben penetrar todos los resquicios del día a día de los individuos.

Cuando Foucault expone,en 1982 en la universidad de Vermont (Foucault, 1988), cómo es que se ha gobernado a los individuos, qué se les ha ofrecido para participar (en sentido fuerte) en un cierto tipo de gobierno, resalta dos elementos para que ello suceda. Por un lado, el Estado se interesa en los individuos, no por un acto de generosidad, sino porque, para el siglo XVII, es claro que la sobrevivencia y consolidación del Estado, requiere de los individuos que lo conforman; será necesario, entonces, desarrollar formas que permitan conocerlos, organizarlos yreproducirlos. Foucault, por otro lado, identifica el desarrollo de una herramientadel Estado diseñada con objetivos precisos, es decir, una técnica (Foucault, 1988: 1639), usadapara lograr su fortalecimiento con base en la injerencia constante y normada sobre las acciones de los individuos; cuando dicha herramienta se difunde y usa en la población, Foucault le llama "tecnología del poder" (Foucault, 1976: cf. 1008-1012), - "tecnologíasgubernamentales" (Foucault, 1984b:1547). Toda tecnología para gobernar, afirma Foucault, contiene tres formasa través de las cuales se constituye durante su despliegue: "un sueño, o mejor, una utopía; también, una práctica de la que sus reglas se inscriben en instituciones en serio; en fin, una disciplina académica." (Foucault, 1988:1640)

La anterior enunciación debemos entenderla, aquí, en sentido amplio, puesto que proponemos extender su aplicación más allá de los espacios de gobierno; la vincularemos con los diferentes canales de expresión de los colectivos que conforman a la sociedad relacionados a partir de: i) prácticas que comparten, ii) formas de ver al mundo, iii) concepción del individuo, y iv) metas a futuro propuestas.

En este trabajo, abordaremos, desde nuestra propuesta de "tecnologías de la democracia", diferentes modos de pensamiento a través de los cuales se difundieron algunos beneficios a obtener cuando el régimen democráticoestuviera instaladol definitivamente; dos de los ejes de dichos beneficios, fueron, sin duda alguna, las ideas de civilización y progreso que penetraron todos los rincones en la vida de los hombres.

tuyéndose o vegetando dolorido, goza de luz, se instruye, se prepara para entrar en la comunidad social." (Prieto, $1874: 78$ ), 


\section{DOS. El despliegue de atmósferas democráticas.}

Cuando en el siglo XIX varios países del continente americano se independizaron del gobierno colonial, requirieron, en lo inmediato, sustituir, no sólo su régimen político, sino su manera de planificar y organizar la nueva sociedad con los habitantes que permanecieron en el territorio. La transición de régimen exigió, por la urgencia de ubicar y promover las nuevas maneras de gobernar y gobernarse, exponer e invitar a nuevas formas para entender a la sociedad naciente $y$, con base en ello, conducirla hacia el modelo decidido. Es claro que, en los primeros años, hubo vaivenes en las decisiones hechas, y las guerras civiles se sucedieron intermitentemente. En 1845, Faustino Sarmiento, recuerda lo que había en Argentina en los inicios de su independencia:

La revolución que llevaría a independizarse del rey, afirma Sarmiento, "era sólo interesante e inteligible para las ciudades argentinas, extraña y sin prestigio para las campañas [campiñas]. En las ciudades había libros, ideas, espíritu municipal, juzgados, derecho, leyes, educación, todos los puntos de contacto y de mancomunidad que tenemos con los europeos...", (Sarmiento, 1845: 64)

A la sociedad de las ideas y la semejanza con los europeos, Sarmiento la califica de ejemplo a seguir y desarrollar; ahí donde la ley está hecha por el cuchillo del gaucho, la llama bárbara y sin atractivo para consolidar un país. El gobernante de Buenos Aires independiente, quería desarrollarla como espacio que veía al futuro, así, Rivadivia, el responsable:

Traía sabios europeos para la prensa y las cátedras, colonias para los desiertos, naves para los ríos, interés y libertad para todas las creencias, crédito y Banco Nacional para impulsar la industria; todas las grandes teorías sociales de la época para modelar su gobierno.... (Sarmiento, 1945: 111).

Las opciones en esos momentos, no podían complicar la elección: con la república y la democracia, el camino estaba listo para el progreso y la mejora del país y la sociedad; cualquier otra alternativa, era estancamiento y atraso. O el ejemplo europeo a seguir, o la bestialidad y el subdesarrollo con aquéllos que no ven más allá del beneficio personal y que son incapaces de un objetivo nacional. Estrictamente hablando, para Sarmiento, el salvaje o bárbaro (como Facundo) es producto de una falta de instrucción y domesticación;

Y sin embargo de todo esto, Facundo no es cruel, no es sanguinario; es el bárbaro, no más, que no sabe contener sus pasiones, y que, una vez irritada, no conocen freno ni medida; es el terrorista que a la entrada de una ciudad fusila a uno y azota a otro.... (Sarmiento, 1845: 169)

Bastará, entonces, educar al gaucho incontrolable, mostrarle las bondades del comercio, del intercambio entre países, del espíritu de 
empresa. Es eso lo que pasará cuando, por la invasión de gauchos poderososcontrolando las ciudades (Rosas o Facundo), los citadinos se mudarán al interior y llevarán las ideas civilizadas a la pampa, provocando así que "se han hecho ciudadanos los gauchos y simpatizado con la causa de las ciudades." (Sarmiento, 1845: 242). El camino prometedor para Argentina sucede, cuando se dan las condiciones para encauzar su desarrollo en los mismos términos que los europeos, cuando los 'bárbaros' de las campiñas ya pueden apreciar las ideas, las leyes, la educación, los libros.

El inicio del México independiente no tiene grandes diferencias, en cuanto al camino a seguir para conformar al país. En la primera década del país liberado, El Iris, periódico crítico y literario, afirma categóricamente que quien no instruya a la gente cercana, o a sus hijos, bajo los valores del Republicanismo liberal, se convierte por ello en enemigo del Estado (El Iris, 1826: 77-78); además, no apreciar a los "extranjeros laboriosos" que han llegado, o al sistema representativo implementado, implicaba oponerse a la ilustración y a la prosperidad.

El Iris, sin embargo, no consideraba que la incomprensión de las bondades republicanas y democráticas fuera producto de falta de educación (como afirma Sarmiento), sino que las ideas que tenían los salvajes mostraban que eran:

... juguetes y víctimas de la más estúpida superstición, mal alojados, groseramente nutridos, cubiertos de paño burdo con un lujo molesto y circunscrito, sin caminos cómodos, con una navegación imperfecta, escasos de relaciones con los pueblos limítrofes, sin comercio, sin literatura, engañados por impostores alquimistas, astrólogos y empíricos.... (El Iris, 1826: 78)

En otros términos, desde El Iris, los bárbaros no están limitados por sus escasas miras para trabajar con el otro, o para reconocer la posibilidad de aumentar sus fuerzas si se reúne gente con intereses comunes, sino que se han alimentado con ideas que promueven la separación, la distancia y el aislamiento; no han tenido contacto con el discurso de la civilización que les mostraría la importancia de la producción en serie, la industria, la salubridad, la urbanización (El Iris, 1826: 79). El gaucho se prefiere a sí mismo por encima de cualquier otra cosa, el salvaje en México está contaminado con ideas que no le permiten disfrutar el buen vestir, desarrollar el transporte, aumentar el comercio, o adquirir modos de vida citadinos e industriales.

La elección de la organización social a instaurar en los Estados americanos independientes, no muestra una discusión en torno a variadas opciones, la implementación oscila entre la opción democrática o la dictatorial (instalada con monarquías e imperios). Ahí donde se establece la democracia, los debates continúan en cuanto al calendario adecuado para desarrollar el aspecto económico, o el 
jurídico, o el social, o todos en conjunto. Porque el progreso está esperando a todos, disfrutarlo es un trabajo individual que, con el régimen político instaurado, será fácil cumplirlo; las imágenes de los frutos de la democracia son calles aireadas, alamedas con fuentes, propiedades de explotación agrícola o urbana, tiempo de descanso, instrucción y conocimientos universales.

Ortiz de Ayala, en 1832, sostiene la necesidad de una policía para la ciudad de México, pero aclara que no es una policía hostil a las condiciones que necesita un pueblo libre, sino:

...nos referimos a ta creación de una magistratura más noble y sublime, compatible con nuestras instituciones y las exigencias de las mejoras sociales, que está demandando imperiosamente el nuevo orden de cosas, a fin de reprimir poco a poco los abusos introducidos por la administración versátil y provisora colonial, y tender al aseo, conveniencias, moralidad y aplicación de un pueblo dócil y predispuesto a los adelantos de la industria y la civilización. (Ortiz de Ayala, 1832: 318-319)

Lo cierto es que, cualquiera lo sabe en el siglo XIX, después de la democracia, lo que sigue es la civilización, que es un resultado inherente a la conquista de la libertad por pueblos que aspiran a mejorar su bienestar y su desarrollo (Otero, 1842: 111); son las naciones que se han hecho acreedoras a garantías sociales y prosperidad pública.

Así como la geometría: ... la civilización también es una ciencia ya adquirida cuyos principios tenemos que aprender y no que inventar, y cuya adquisición es tanto más fácil cuanto mayores son los adelantos y más perfectos y sencillos los medios para adquirirlos. La civilización no es más que la expresión de esa ley de perfectibilidad que tiende a elevar al hombre físico y al hombre moral, y ella no es la ley de un pueblo sino de la humanidad entera: por eso ha invadido a todas las naciones y los pueblos con una fuerza irresistible. (Otero, 1842: 83, sub. nuestros)

La explicación no puede ser más redonda: justo porque es ineluctable en los hombres buscar su mejora, yla satisfacción de sus necesidades físicas y morales, hacerlo a través del Estado democrático, es una práctica que se extiende en el planeta. Los elementos que pueden participar en la civilización siempre han existido, sólo que estaban articulados de manera distintas; ahora, para que consoliden al Estado instaurado, es necesario reordenarlos: desde la organización de las ocupaciones de las poblaciones, hasta el establecimiento de una de las herramientas más fructíferas para acercar, a la mayor cantidad de individuos, con las ideas precisas y concretas derivadas de la democracia, una tecnología conformada por múltiples tácticas:la instrucción y educación. 
Las clases industriosas y trabajadores, afirma Otero, se convertirán en el sustento de la República, porque en cuanto tengan recursos materiales y morales que las liberen de los yugos anteriores, después, buscarán aumentar sus conocimientos y mejorar su vida (Otero, 1842: 88-89). Además, no sólo es cuestión de trabajo o de instruirse, también hay que mostrarles cómo se puede vivir de otra manera, es decir, el modo de vida al que se debe aspirar desde el nuevo país, que pretende inscribirse en esquemas ilustrados, cultos y educados.

El banco de ahorros y previsión, que ha indicado el secretario de relaciones desde 1830, debería efectuarse por la saludable tendencia que resulta a las clases jornaleras, en orden a contraer el hábito de la economía, y aspirar un día a que todos los obreros mexicanos, como todos los de los países cultos, economizando una parte de sus salarios, adelanten en cuanto a los goces sociales y contraigan nuevas necesidades para hacerlos más aplicados, laboriosos y menos pródigos de sus cortos ahorros. (Ortiz de Ayala, 1832: 323, sub. nuestro)

La democracia, así divulgada, ofrece una visión de seguridad obtenida con la decisión individual depositada en el gobierno; rápidamente, se encuentra la vía que promete solemnemente el acceso al ejercicio democrático: la instrucción para toda la población. Benito Juárez, presidente de México en 1861, elogia:

...los constantes afanes de la junta para difundir en México la instrucción primaria en la clase menesterosa del pueblo, con el fin de inculcarle los principios que deben engendrar en él las virtudes locales, sin las cuales jamás podrá alcanzar el conocimiento de sus deberes y la apreciación de sus derechos. (Juárez, 1861:114).

Educar e instruir al pueblo tiene sentido en los gobiernos que pretenden la igualdad,la responsabilidad de los ciudadanos y la protección jurídica... como promesa que guía para seguir el camino trazado.

En otras latitudes, la instauración de la educación buscaba otros objetivos. Es lo que sucede en Perú, cuando Mariátegui expone las razones por las cuales, el nuevo gobierno peruano ofrece educación gratuita para todos.

El gobierno de 1831, que declaró la gratuidad de la enseñanza [... en realidad] Lo que preocupaba a ese gobierno, no era la necesidad de poner este grado de instrucción al alcance del pueblo. Era, según sus propias palabras, la urgencia de resolver un problema de las familias que habían sufrido desmedro en su fortuna. (Mariátegui, 1928: 95)

Recordemos el hilo conductor en el planteamiento de Mariátegui: los indígenas en Perú han sido olvidados y menospreciados en los diferentes ámbitos de organización del país (cf. Mariátegui, 1928: cap. 2). Siendo una nación con un porcentaje mayoritario de indígenas, dice Mariátegui, ¿̇cómo es que no se les ha podido dotar de condiciones 
democráticas para vivir? Las respuestas venían desde una perspectiva política, y no económica; la respuesta política descansa en cuestiones insuficientes para resolverlo: la raza, la cultura, la moral; elementos todos que eluden el verdadero problema.

La ejecución de un programa demoliberal resultaba en la práctica entrabada y saboteada por la subsistencia de un régimen de feudalidad en la mayor parte del país. No es posible democratizar la enseñanza de un país sin democratizar su economía y sin democratizar, por ende, su superestructura política. (Mariátegui, 1928:106)

En el caso peruano, y desde esta lectura de principios del siglo XX, la democracia no es puesta en duda, sino los fundamentos que le otorgan fuerza: mientras sólo incorpore cuestiones que son accesorias y secundarias a la cuestión económica, ningún pueblo podrá decirse gobernado bajo las ideas de igualdad y representación de todos en el gobierno.

La democracia tiene, también, una arista que atañe al cuerpo mismo de cada individuo y que, con la dinámica del papel del Estado, irá afinando sus compromisos que pasarán de la seguridad física frente a cualquier extranjero invasor, a especificarse en ofrecimientos con base en las etapas de vida de las poblaciones: la atención a la infancia, la adolescencia y los adultos, requerirán echar a andar grandes circuitos de atención (con el personal capacitado incluido). Los sistemas de higiene y salud públicas evidenciarán (Noir, 1896; Lamounette, 1897; Pavía, 1903), de manera incuestionable, el avanzar concreto de la igualdad en, i) protección a la población de enfermedades masivamente dañinas; ii) la idea de salud como parte de la vida de las personas, ii) la salud durante la vejez, iii) cuidados en el desenvolvimiento de una población sana y trabajadora, iv)vigilancia en la reproducción de los habitantes (enfermedades hereditarias, mezclas con inmigrantes portadores de caracteres de razas distintas, efectos del alcoholismo y las drogas).

En sus inicios, la higiene pública, privada e industrial, o la salud por enfermedades contagiosas, por alimentación, por el vestido, por las condiciones de las habitaciones, eran un conjunto de información transmitido en bloque. Adelante abordaremos situaciones precisas sobre las consecuencias de introducir circuitos de higiene y salud (implementados desde los gobiernos) con concepciones de modernidad y consumo. Por el momento, veamosla protección al cuerpo y el cultivo de la salud promovidos por Heriberto Frías, escritor y periodista mexicano, en una de sus novelas:

Convirtió al fin en realidad de acción los pensamientos que ilumináranle en su tercera etapa de cárcel, recordando su convicción de que al punto la salud se convierte en alegría y en luz, en trabajo que es dignidad y en dinero que es fuerza y es todo, en nobleambición de 
mejorar todavía. No olvidaba que muchas veces se había convencido de que todo el problema nacional no era sino cuestión de salud; que la regeneración era imposible, lo mismo al individuo que a la raza mientras fuera débil y enferma; que atender a síntomas y manifestaciones, cambiando sólo de formas, regímenes y gobiernos no es curar... Pensaba que un individuo es lo mismo que un pueblo raquítico, porque sus hombres son débiles, prontos al yugo, si se humilla causa lástima, y es ridículo si protesta. (Frías, 1916: 229,sub. nuestros)

El comentario de Frías se desarrolla en dos niveles, el superficial de las consecuencias, y el profundo de las condiciones. Si el individuo quiere ir más allá de su caer en lo más bajo de la sociedad, como le sucede a su personaje que llega a la cárcel, no le va a servir mucho cambiar sus actividades, necesita transformar su cuerpo, fortalecerlo a través de la alimentáción, darle consistencia desde dentro para que crezca, para que se desarrolle ${ }^{8}$ y deje atrás las medidas minúsculas y simuladoras; es lo mismo para la población que, con los programas del gobierno tocando sólo la superficie, no podrá aventurarse en la mejora de su presencia, de su ser interior, no podrá trabajar ni obtener la fuerza que da el dinero. El pueblo entero debe poseer un cuerpo saludable: "Sólo la salud del individuo haría tranquilo y rico su hogar; sólo la salud de la raza hará próspera y digna a la patria." (Frías, 1916:239)

El pasaje por el cuerpo para organizar a la sociedad fue un elemento común a las nuevas democracias, porque estaba en la mesa de las discusiones en quienes disertaban sobre la forma de organizar a las sociedades (cf. Foucault, 2004a, 2004b; Pichot,2000: cap. 1). El viento levantado por las obras de Darwin o de Pasteur, se inscribe en el estrecho vínculo que la física y la química han tejido con las oficinas de gobierno para ofrecer productos 9 nuevos dirigidos a la cotidianidad de las personas.

Si las tecnologías de la democracia abundan en la utopía o el sueño que se puede alcanzar con este régimen de gobierno, insistamos, nunca ha podido ser sin exaltar sus "consecuencias inevitables": ofrecen que los integrantes de la sociedad serán acreedores, directa 0 indirectamente, al progreso social y al bienestar de vida. Los modos a través de los cuales se ha gobernado, finalmente, en el democrático mundo occidental, no pueden ser juzgados como imposiciones puras, ni

\footnotetext{
8. "Y fuerte con estas razones y con el amor de Fina y con la ausencia de alcohol y con la buena carne asada y los huevos crudos que almorzaba, y con la esperanza de vestir decentemente su vivienda y su persona y de alegrar el duelo de su esposa que lloraba a sus hijos arrebatados para robarles una herencia, fuerte con tanta fuerza, Miguel creyó vencer definitivamente." (Frías, 1916: 229).

9. Recordemos, por ejemplo, que Faraday es nombrado "consejero científico" en el Trinity-House, la Dirección de servicio de luminarias en Inglaterra (Tyndall, 1879: 791). En el siglo XX, además del caso del equipo constructor de la bomba atómica (Manhattan Project), recordemos la larga coordinación posterior que hace V. Bush (1945) en los Estados Unidos, y su imitación en Inglaterra y Francia.
} 
como manipulaciones perversas; comprender su eficacia exige reconocer la complejidad del entramado; se trata de evidenciar el funcionamiento y engranaje de los diferentes modos de pensamiento, dispuestos a consolidar la línea trazada por la democracia, en un mundo que necesitaba incorporar a todos en una misma aventura 10: el viaje donde los límites sólo pueden pensarse como reto a superar.

\section{TRES.La espuma que escurre de los argumentos democráticos.}

En el entramado irregular para la organización de las sociedades democráticas, podemos identificar las directrices expresadas con reglamentos, leyes, manuales, políticas que serán los puntos de anclaje y las redes de protección del correcto camino a seguir. La necesidad normativa no es un mero trámite prescriptivo; la argumentación de las reglas abre las puertas para difundir, sin cansancio, las bondades esperadas, los logros a alcanzar y el triunfo y reconocimiento que, tarde - temprano, llegarán. Las reglas que se pueden estudiar desde las tecnologías del gobierno son insuficientes para el planteamiento que aquí se sostiene, pues el hacer del Estado no podría dar cuenta, por sí mismo, del convencimiento de las poblaciones sobre las formas de vida y el sentido de lo que se hace; sin los discursos complementarios desde la cultura, las obras artísticas, las disciplinas, las múltiples manifestaciones populares (música, rumor, chistes, danza, tradiciones, mitos), la democracia y sus beneficios, no serían asumidos, reproducidos, aceptados, defendidos.

El 5 de diciembre de 1887, en la ciudad de México, Justo Sierra, responsable de la instrucción pública, argumentaba, frente a las objeciones expuestas en la cámara de diputados, la necesidad de que los niños, hijos "de los indios", asistieran a la escuela. El primer argumento de Sierra fue que no era posible hacer una distinción entre los niños de la "capital" y los de provincia, con base en el respeto a las leyes del país que se está forjando: "¿no se rompe con esto la unidad de la ley, y no se rompe de una manera injustificable e insostenible ante la luz de los principios democráticos?" (Sierra, 1887: 211). Los diputados mexicanos demócratas no pueden permitirse hacer a un lado los fundamentos políticos del país, aunque, la objeción principal de algunos diputados a la propuesta, fue que los niños eran necesarios para apoyar el trabajo de su padre. Sierra, continuando en la línea legal, con "un reporte entre las manos" que puso a disposición de la Cámara, indica que los "países civilizados" ya mostraron lo indefendible de ese argumento familiar; dichos países, en consecuencia con su argumentación y para resolver el problema, lo que hicieron fue legislar el trabajo de la niñez.

10. Referencia obligada de la ciencia que todo lo puede: J. Verne (1867). 
En todas partes el problema social del trabajo del niño se presenta en condiciones aterradoras; ¿̇y en qué sentido se ha resuelto? En el sentido de obligar al padre a no hacer trabajar a su hijo sino hasta cierta edad, porque de otra manera se segaban en flor las esperanzas futuras de los países civilizados. (Aplausos). (Sierra, 1887: 214. Sub. nuestros)

Porque es claro, afirma Sierra, que, en Francia, los niños menores de doce años, no pueden trabajar en ingenios, minas, obradores ni talleres, aunque, si se trata de hilanderías, lo pueden hacer desde los "diez años cumplidos". En Prusia, gracias a la ley de mayo de 1853, los niños entre doce y catorce años, sólo pueden trabajar seis horas "y deben frecuentar la escuela durante tres horas cuando menos" (Sierra, 1887: 214). En Inglaterra, de manera terminante, los niños menores de diez no pueden trabajar; en Bélgica y los Países Bajos, si el menor trábajará en el servicio doméstico o el trabajo rural, lo puede hacer con menos de doce años, "... y estas disposiciones cuyos pormenores constan en el apunte que tengo en las manos, no son disposiciones platónica, sino sancionadas con multas de diez a quinientos pesos y con prisión de cinco días a diez meses." (Sierra, 1887: 215)

La obligatoriedad para asistir a la escuela fue aprobada en ese mismo año de 1887, y los testigos de los debates, aprendieron como, siguiendo las leyes de los países civilizados ${ }^{11}$, el trabajo de los infantes podía ser legalmente autorizado. Pero, es claro, no es por la equidad o justicia que guardan los argumentos por lo que se aprueban las leyes, sino porque en la negociación inherente al ámbito democrático, el tema implícito al que aludía Sierra, era al uso de trabajadores infantes, que sería, a partir de ese momento, considerado dentro de la ley. La necesidad de legalizarlo era antigua y los legisladores podían felicitarse de obtenerlo.

También hay otros espacios desde los cuales difundir atenciones democráticas para la niñez. En las primeras décadas del siglo XX, las ideas sobre un cuerpo sano, la necesidad de cuidar el crecimiento de los niños, se pueden localizar en diferentes espacios públicos, textos, obras de expresión creativa, entre otros. Sin embargo, antes de que un individuo (como ya vimos que lo hace Frías) pueda formularse esas preocupaciones, fue necesario que los diferentes modos de pensamiento en la organización de la sociedad generaran las condiciones para expandir su pertinencia: la literatura, los periódicos, los discursos políticos, los saberes teóricos sistematizados, la fotografía. Es decir, para que un individuo pueda pensar, no en mantener su cuerpo, no en mantenerse vivo, sino, en tener un cuerpo que además esté sano, fue necesario cultivar y difundir información que prepararía el "caldo de cultivo" donde dichas ideas podrían germinar. Colombia no es ajena a "1. En el Manual de Higiene de J. Courmont (1914), traducido al español en 1944, se
encuentran observaciones semejantes para el trabajo infantil; ver p. 527-540. 
estas distinciones; tomar en cuenta al cuerpo desde la política (Pedraza, 1999: 191, 193), incluyó las preocupaciones por la raza, la herencia genética, la mejora de su vigor y el control de sus reacciones (pasiones). El cuerpo pudo convertirse en un instrumento de modernización de la población, tanto en sus actividades como en las concepciones sobre sUS USOS.

La cultura física se extendió apoyada en los deportes y destacó en ellos la belleza, el placer y la felicidad. En la pluma de los columnistas palideció el grueso de los matices moralistas y en su lugar se fustigaron el aspecto lúdico y el sentimiento de independencia que representaba el deporte. En las primeras décadas del siglo [siglo XX] se enaltecieron estas prácticas porque estimulaban las facultades creativas, el arrojo, el liderazgo, el sentido de competencia, la integridad, la distinción y el enriquecimiento intelectual. Su estimación varió el tono del discurso, sobre todo cuando, además del deportista, apareció el espectador y del cultivo del propio cuerpo se pasó al culto al cuerpo ajeno. (Pedraza, 1999: 241)

¿Y qué es organizar a la sociedad, si no seducir a los individuos con formas de vida, con proyectos de existencia, con figuras de imitación atractivas? Porque la democracia es un digno desafío, sus participantes son héroes, líderes, ayudantes, cómplices y colaboradores, todos dispuestos a ocupar su lugar en el colectivo. La democracia fue el camino encontrado para esparcir la buena nueva, "todos seremos incluidos en las decisiones, seremos iguales ante la ley, alcanzaremos juntos una buena vida"; quienes trabajan porque se alcancen tan altos objetivos, se convierten en generosos partícipes del proyecto de todos. No sólo los políticos, o los responsables de las oficinas de gobierno, sino todo aquel que exponga la comprensión y promueva su adhesiónserá incorporado como un apoyo más en la larga lucha. Aspirar a la democracia, se convirtió en el fistolprendido en la ropa que distingue a los individuos buenos.

\section{A manera de conclusión.}

En el análisis desde las tecnologías de la democracia, las fronteras disciplinares se evidencian irrelevantes, porque la propuesta es atravesar las diferentes racionalidades, las que sean, desde las prácticas mismas $y$, en consecuencia, las restricciones propias de un marco teórico-disciplinar resultan improcedentes. En este último, los umbrales de la disciplina ${ }^{12}$ están sustentados en el objeto de estudio y las metodologías legitimadas para abordarlo, mientras que, desde nuestra

\footnotetext{
12. Herman Heller, al expresar sus dudas sobre la fortaleza de la "ciencia política", se apoya en los dos elementos que rigen al discurso-teórico-sistematizado: "la disciplina [ciencia política] carece o bien de un conjunto de problemas claramente delimitado o bien de una metodología definitivamente prescrita.", (Heller, 1934: 88).
} 
propuesta, se trata de ubicar los movimientos, las prácticas de los hombres que se deslizan en una cierta dirección (la democracia, la civilización, el progreso, entre otros), hacia un cierto objetivo (igualdad, confort, mejora, por ejemplo).

El análisis de las "tecnologías de la democracia" aquí expuesto, sólo adquiere fuerza, espesor y pertinencia al exigirse evitar el uso de las cuadrículas oficiales de estudio (las de los gobiernos, o las de las disciplinas), instauradas en los últimos doscientos treinta años. Es por ello que, al inicio, señalamos no retomar las líneas de estudio del Estado, del derecho, ni de las instituciones. Desde diversas disciplinas, ciertamente, la comprensión de las sociedades ha navegado en esos canales, que no pueden más que repetir la cuadrícula político-social implementada (cf. Habermas, 2002; Giddens, 2004; Paredes, 201313; por ejemplo), porque su objetivo es mostrar, de una manera escrupulosa (ciertamente) las tensiones del momento, así como señalar algunas pistas que podrían, eventualmente, disminuir los conflictos, las desigualdades o las simples diferencias que las provocan. En nuestro caso, la pretensiónes introducirnos con instrumentos que penetren, que perforen las condiciones con base en las cuales emergen las ideas de democracia (y sus derivados); identificar cuáles han sido las estrategias usadas en el juego de la relaciones de fuerza al discutir contenidos y alcances.Buscamos otro modo de pensar nuestras prácticas democráticaspues, en el siglo XXI, siguen ofreciendo un mañana mejor inminente, el progreso inextinguible para todos los ciudadanos, en fin, un ejercicio de igualdad que, cada vez más, sonel futuro que se aleja y se pierde en el horizonte.

\section{Bibliografía.}

Bush, Vannevar (1945), Science, the endless frontier. A report to the President on a Program for Postwar Scientific Research, Washington, D. C.: National Science Foundation.

Cardoso, Fernando Henrique (1986), "La democracia en las sociedades contemporáneas", en J. Labastida (coord.) Los nuevos procesos

\footnotetext{
13. En la propuesta de Paredes, se conjuntan dos posiciones teóricas disciplinares, donde una (la de Zemelman) mantiene la necesidad "epistémica", es decir con pretensión de producir conocimiento, que ofrece "abrir caminos" a través de métodos (Paredes, 2013: 127) y, la otra (de De Sousa Santos), la necesidad de indicar cómo alcanzar soluciones y respuestas colectivas emancipadoras, con la mirada puesta en ofrecer aliviar tensiones. "Ambos autores proponen el vínculo entre la cuestión epistemológica y la cuestión sociopolítica para la formulación de alternativas a la naturalización del orden social." (Paredes, 2013: 129).
} 
sociales y la teoría política contemporánea, México: Siglo XXI, P. 345353.

Courmont, Julio, Lesieur, Ch., Rochaix, A. (1914/1944), Manual de Higiene, Madrid : Espasa-Calpe, S. A.

El Iris. Periódico crítico y literario, (1826 / 1986), "Civilización", N²3, Tomo 2, $2^{\circ}$ trimestre, Sábado 3 de junio de 1826, Ed. facsimilar, México: UNAMIIBibliográficas, p. 77-80.

Elster, Jon (1998), Justicia Local, Barcelona:Gedisa.

Espinosa, Julieta (2014), "Modos y plataformas de pensamiento », en J. Espinosa, A. D. Robert, Epistemología social, pensamiento crítico, México: Juan Pablos Editor / UAEM / EcoleDoctorale EPIC - Université de Lyon, p. 13-38.

Foucault, Michel (1966/2001), "Michel Foucault, Les Mots et les Choses ", en Dits et Ecrits I, Paris : Gallimard-Quarto, p. 526-532.

Foucault, Michel (1975/2001), «Des supplices aux cellules », Dits et Ecrits I, Paris : Gallimard-Quarto, p. 1584-1588.

Foucault, Michel (1976/2001), "Les mailles du pouvoir », en Dits et Ecrits II, Paris : Gallimard-Quarto, p. 1002-1020.

Foucault, Michel (1984a/2001), "Préface à l'Histoire de la sexualité", enDits et Ecrits II, Paris : Gallimard-Quarto, 1397-1401.

Foucault, Michel (1984b/2001), "L'éthique du souci de soi comme pratique de la liberté ॥, en Dits et Ecrits II, Paris: Gallimard-Quarto, p. 1527-1548.

Foucault, Michel (1988/2001), «La technologie politique des individus. Université du Vermont, octobre 1982 ॥, en Dits et Ecrits II, Paris : GallimardQuarto, p. 1632-1647.

Foucault, Michel (2004a), Sécurité, territoire, population (1977-1978), M. Senellart éd., Paris: Gallimard-Seuil (Hautes Études).

Foucault, Michel (2004b), Naissance de la biopolitique, Cours au Collège de France 1978-1979, M. Senellart éd., Paris: Gallimard-Seuil (Hautes Études).

Frías, Heriberto (1916/2004), Miserias de México, México:Conaculta Lecturas mexicanas.

Giddens, Anthony (2001), Más allá de la izquierda y la derecha, Madrid: Cátedra.

Giddens, Anthony(2004), La transformación de la intimidad, Madrid: Cátedra.

Girard, René (1985), La route antique des hommes pervers, Paris: Grasset. 
Goffman, Erving (1973), La mise en scène de la vie quotidienne 1 - 2, Paris : Les Éditions de Minuit.

Habermas, Jürgen (2002), Teoría de la acción comunicativa, I y II, México: Taurus.

Heller, Herman (1934/1996), "La ciencia política", en El sentido de la política y otros ensayos, Valencia: Pre-Textos, p. 87-126.

Juárez, Benito (1861/1972), "La educación del pueblo, primera atención de todo gobierno", en Antologia, ed. J. L. Tamayo, México:UNAM, p. $114-$ 115.

Lamounette, B. (1897), Elementos de Higiene, México: Imprenta de Eduardo Dublán, Callejón de $57 \mathrm{~N}^{\circ} 7$.

Latour, Bruno (2010), Cogitamus, Paris : La Découverte.

Latour, Bruno (2012), Enquête sur les modes d'existence. Une anthropologie des Modernes, Paris, La Découverte.

Mariátegui, José C. (1928 / 1979), Siete ensayos de interpretación de la realidad peruana, México: Serie popular ERA.

Nietzsche, Friedrich (1886 / 1989), Le Gai Savoir, trad. J. Hervier: Paris, Gallimard.

Noir, Julien, (1896), Hygiène, Bibliothèque du conducteur de travaux publics, Paris: Vve. Ch. Dunod et P. Vicq, Editeurs, Libraires des Ponts et Chaussées, des Mines et des Chemins de Fer, 49, Quai des GrandsAugustins.

North, Douglass C. (2001), Instituciones, cambio institucional y desempeño económico, México: FCE.

Ortiz de Ayala, Tadeo (1832/1996), México considerado como nación independiente y libre, México:ConACULTA - Cien de México.

Otero, Mariano (1842/1964), Ensayo sobre el verdadero estado de la cuestión social y política que se agita en la República Mexicana, México: Instituto Nacional de la Juventud Mexicana.

Paredes, Juan P., (2013), "Pensamiento epistémico y conocimiento social: emergencias y potencialidades en la investigación social", Revista de Estudios Sociales, № 48, Enero-Abril 2013, Bogotá:125-138.

Pavía, Lázaro (1903), Nuevo guía del profesor o Nuevo manual del maestro. Obra arreglada i extractada de lo más selecto de publicaciones i escritos de autores mejicano i extranjeros, México: Imprenta de Eduardo Dublán, Callejón de Cincuenta i Siete, Num. 7.

Pedraza, G., Zandra (1999), En cuerpo y alma. Visiones del progreso y de la felicidad, Bogotá: Universidad de los Andes.

Pichot, André (2000), La société pure. De Darwin à Hitler, Paris: Flammarion. 
Prieto, Guillermo (1874 / 1997), "Salas de asilo», en Obras Completas, Vol. XXV, México :CONACULTA, p. 75-79.

Quermonne, Jean-Louis (1986), Les régimes politiques occidentaux, Paris : Editions du Seuil.

Rosanvallon, Pierre (2011), La société des égaux, Paris : Editions du Seuil.

Sarmiento, Domingo F. (1845 / 1982), Facundo o civilización y barbarie, México: SEP / UNAM.

Sierra M., Justo, (1887), "(Varias sesiones). Dictamen y discusión del proyecto de ley que da bases para la organización de la enseñanza primaria obligatoria", en Sierra, J. Obras completas. Vol. VII, La Educación Nacional, México: UNAM, p. 164-219.

Sloterdijk, Peter (2010), Sphère II. Globes, Paris : Fayard-Pluriel.

Sloterdijk, Peter(2011), Tu dois changer ta vie, Paris : Libella.

Sloterdijk, Peter (2015), Los hijos terribles de la edad moderna, Madrid :Sirvela.

Smith, Adam (1776 / 1994), An Inquiry into the Nature and Causes of the Wealth of Nations, New York: The Modern Library.

Stengers, Isabelle (2009), Au temps des catastrophes, Paris: La Découverte.

Stengers, Isabelle (2013), Une autre science est possible!, Paris: Les empêcheurs de penser en rond.

Touraine, Alain (2013), La fin des sociétés, Paris :Editions du Sevil.

Tyndall, John (1879), "La lumière électrique », en Revue Scientifique de la France et de l'étranger, 2e série, 8e année, № 34, 22 février 1879: 789798.

Verne, Jules (1867 / 1994), Voyage au centre de la Terre, Paris: Hachette. 